\title{
RENCANA DESAIN BACKFILLING DAN PERHITUNGAN VOLUME MATERIAL TIMBUNAN MENGGUNAKAN SOFTWARE MINESCAPE 4.118 UNTUK MEMENUHI TARGET PRODUKSI
}

\section{BACKFILLING DESIGN PLAN AND STOCKPILE MATERIAL VOLUME CALCULATION USING MINESCAPE 4.118 SOFTWARE TO REACH PRODUCTION TARGET}

\author{
Riska Yuliana $^{1)}$, Sepriadi $^{2}$ \\ 1Program Studi Teknik Pertambangan Batubara Politeknik Akamigas Palembang, 30257, Indonesia \\ 2Program Studi Teknik Pertambangan Batubara Politeknik Akamigas Palembang, 30257, Indonesia \\ Corresponding Author E-mail: riskayuliana014@gmail.com dan sepri@pap.ac.id
}

\begin{abstract}
The backfilling design plan process in the West Pit of Muara Tiga Besar (MTB) was conducted using Minescape 4.118 software. Before making the disposal design, bench height, width, slope, haul road width, and simulation map were prepares. The stage of making disposal designs began from making oundary, projects and offsets, triangles, intersection of disposal and situation sedigns, clip world, cross section, and ploting. Calculation of stockpile volume was found in the reserves bar menu (triangle cut and fill). The overburden production inthe West Pit April 2019 with clasy siltstone material utilized Minescape 4.118 software using a parameter assumption of 1.724.805,98 CCM with a production target of $1.700 .000 \mathrm{CCM}$ and the production in the field based on the design made by the company was 1.500.000 CCM. The production different was caused by several factors, namely taking the coordinate points from the activities of the survey team, road conditions, equipment consitions, operator performance, and supervision.

Keywords: Disposal design, stockpile volume, production target
\end{abstract}

Abstrak: Proses rencana desain backfilling pada area pit Barat Muara Tiga Besar (MTB) dilakukan menggunakan software Minescape 4.118. Sebelum pembuatan desain disposal yang dipersiapkan ialah tinggi bench, lebar bench, kemiringan bench, lebar jalan angkut, dan peta situasi. Tahapan pembuatan desain disposal dimulai dari pembuatan boundary, pembuatan project dan offset, pembuatan triangles, pembuatan intersection desain disposal dan situasi, clip world, cross section, dan plotting. Perhitungan volume timbunan terdapat pada menu bar reserves (triangle cut and fill). Produksi overburden di pit Barat pada bulan April tahun 2019 dengan material clay siltstone menggunakan software Minescape 4.118 dengan menggunakan asumsi parameter sebesar 1.724.805,98 CCM dengan target produksi sebesar 1.700.000 CCM dan produksi di lapangan sesuai desain yang dibuat oleh pihak perusahaan sebesar 1.500 .000 CCM. Selisih produksi tersebut disebabkan beberapa faktor, yaitu pengambilan point koordinat dari kegiatan tim survey, kondisi jalan, kondisi alat, kineja operator, dan pengawasan.

Kata Kunci : desain disposal, volume timbunan, target produksi

\section{PENDAHULUAN}

\subsection{Latar Belakang}

Pada tambang terbuka, kegiatan awal dari proses penambangan adalah pembersihan lahan, pengupasan overburden atau tanah penutup yang berada di atasnya dan pengambilan endapan batubara. Overburden merupakan material yang tidak berharga yang harus digali dari pit agar batubara dapat ditambang. Overburden yang telah dikupas dipindahkan ketempat penimbunan yang biasa disebut dengan disposal. Disposal merupakan daerah pada lokasi operasi tambang terbuka yang dijadikan tempat untuk membuang atau menimbun material yang tidak berharga.

Di PT Bukit Asam, Tbk. khususnya pada area penambangan tambang Muara Tiga Besar (MTB), menerapkan sistem in pit dump atau backfilling untuk kegiatan penimbunan material galian kupasan tanah penutup. In pit dump atau backfilling adalah lokasi disposal yang merupakan lokasi lahan bekas lereng yang telah ditambang yang pada waktu tertentu saat lokasi penimbunan sudah final akan dilakukan revegetasi.

Penimbunan overburden dengan
metode backfilling bertujuan untuk


mengurangi ongkos produksi dengan memperpendek jarak angkut dan untuk mempercepat proses reklamasi. Di pit barat Muara Tiga Besar pada bulan April tahun 2019 target produksi sebesar 1.700.000 CCM, dengan desain yang dibuat perusahaan produksi yang tercapai hanya sebesar 1.500.000 CCM. Oleh karena itu penulis ingin merekomendasi desain disposal baru dengan harapan target produksi tercapai. Pembuatan disposal memerlukan suatu lahan, luas area disposal yang akan dibutuhkan, daya tampung disposal, dan lain sebagainya. Dari hal tersebut, maka menjadi dasar untuk melakukan penelitian ini mengenai desain disposal area dan perhitungan volume material timbunan.

\subsection{Batasan Masalah}

Batasan masalah dalam penelitian ini, penulis hanya membahas untuk:

1. Lokasi disposal di pit Barat Muara Tiga Besar (MTB) PT Bukit Asam, Tbk..

2. Menghitung volume overburden di Muara Tiga Besar pit Barat yang akan ditimbun pada disposal area pada bulan April tahun 2019.

Desain jalan angkut disposal dibuat berdasarkan alat angkut HD 785-7 PT Bukit Asam, Tbk. dan sesuai standar AASHTO.

\subsection{Tujuan Penelitian}

Tujuan dari penelitian ini adalah :

1. Mengetahui parameter dan tata cara pembuatan rencana desain backfilling di Muara Tiga Besar pit Barat PT Bukit Asam, Tbk. pada bulan April tahun 2019.

2. Menghitung perhitungan volume disposal dengan menggunakan software Minescape 4.118 di Muara Tiga Besar pit Barat untuk memenuhi target produksi overburden di bulan April tahun 2019

3. Membandingkan volume overburden menggunakan software Minescape 4.118. dengan realisasi di lapangan.

\subsection{Manfaat Penelitian}

Manfaat dari penelitian ini adalah

1. Mampu memodelkan rencana desain backfilling di Muara Tiga Besar pit Barat PT Bukit Asam, Tbk. pada bulan April 2019.
2. Mampu menjelaskan cara perhitungan volume disposal dengan menggunakan software Minescape 4.118.

3. Mampu mengidentifikasi perbandingan antara volume menggunakan software Minescape 4.118 dengan realisasi di lapangan.

\section{TEORI DASAR}

\subsection{Perencanaan Secara Umum}

Perencanaan adalah penentuan persyaratan teknik pencapaian sasaran kegiatan dan urutan teknik pelaksanaan dalam berbagai macam anak kegiatan yang harus dilaksanakan untuk mencapai sasaran dan tujuan kegiatan. Masalah perencanaan tambang merupakan masalah yang kompleks karena merupakan problem geometrik tiga dimensi yang selalu berubah dengan waktu dan akan menjadi fokus utama. Untuk itulah diperlukan perencanaan yang matang sebelum melakukan kegiatan penambangan untuk meminimalkan berbagai masalah yang akan terjadi (Irwandi dan Adisoma, 2002).

Macam-macam perencanaan tambang adalah

1. Perencanaan jangka panjang (yearly), yaitu suatu pemodelan rencana kegiatan yang jangka waktunya lebih dari 1 tahun secara berkesinambungan.

2. Perencanaan jangka menengah (quarterly), yaitu suatu pemodelan rencana kerja untuk jangka waktu 3 bulanan.

3. Perencanaan jangka pendek (daily/weekly), yaitu suatu pemodelan rencana aktifitas untuk jangka waktu harian/mingguan.

\subsection{Metode Pengupasan Tanah Penutup (Overburden)}

Pengupasan tanah penutup (overburden) adalah kegiatan lanjutan setelah pekerjaan land clearing. Pada tahapan pekerjaan overburden, peralatan yang digunakan telah mengalami penambahan, yaitu: bulldozer, excavator, dan dump truck.

Hal yang harus diperhatikan dalam melaksanakan pengupasan overburden adalah tahapan penggalian yang harus dilakukan secara benar, yaitu penggalian tanah humus harus dipisahkan dengan overburden di 
bawahnya. Hal ini dimaksudkan, agar pada saat kegiatan reklamasi bekas lahan tambang membutuhkan tanah humus dapat dengan mudah dimobilisasi kembali. Karena, secara teknis sifat dan karakteristik tanah humus dengan tanah di bawahnya sangat jauh berbeda (Sudrajat, 2013 : 135).

Beberapa metode dalam pengupasan tanah penutup (overburden) antara lain :

\section{Backfilling digging method}

Pada cara ini overburden dibuang ke tempat yang batuannya sudah digali. Peralatan yang banyak digunakan adalah power shovel atau dragline. Bila yang digunakan hanya satu buah peralatan mekanis, power shovel atau dragline saja disebut single stripping shovel/dragline dan bila menggunakan lebih dari satu buah power shovel atau dragline disebut tandem stripping shovel/dragline.

Cara backfilling digging method cocok untuk overburden yang bersifat :

a. Tidak diselangi oleh berlapis-lapis endapan bijih (hanya ada satu lapis).

b. Material atau batuannya lunak.

c. Letaknya mendatar (horizontal).

2. Benching system

Cara pengupasan lapisan overburden dengan sistem jenjang (benching) ini pada waktu pengupasan lapisan overburden sekaligus sambil membuat jenjang. Sistem ini cocok untuk :

a. Overburden yang tebal, dan

b. Bahan galian atau lapisan batu gamping yang juga tebal.

\section{Multi bucket excavator system}

Pada pengupasan cara ini overburden dibuang ke tempat yang sudah digali batu gampingnya atau ke tempat pembuangan khusus. Cara ini ialah dengan menggunakan bucket wheel exavator (BWE), sistem ini cocok untuk overburden yang materialnya lunak dan tidak lengket.

\section{Drag scraper system}

Cara ini biasanya langsung diikuti dengan pengambilan bahan galian setelah overburden dibuang, tetapi bisa juga overburden-nya dihabiskan terlebih dahulu, kemudian baru bahan galiannnya ditambang.
Sistem ini cocok untuk overburden yang materialnya lunak dan lepas (loose).

5. Cara konvensional

Cara ini menggunakan kombinasi alatalat pemindahan tanah mekanis (alat gali, alat muat, dan alat angkut) seperti kombinasi antara bulldozer, wheel loader dan dump truck. Bila material overburden lunak bisa langsung dengan menggunakan alat gali muat, sedangkan bila materialnya keras mungkin menggunakan ripper atau pemboran dan peledakan untuk pembongkaran overburden, baru kemudian dimuat dengan alat muat ke alat angkut, dan selanjutnya diangkut ke tempat pembuangan dengan alat angkut.

\subsection{Disposal}

Disposal adalah suatu tempat yang dijadikan untuk pembuangan overburden. Penentuan lokasi disposal perlu diperhatikan agar tidak mengganggu proses eksploitasi pada saat sekarang hingga akhir tambang. Untuk luasan disposal dirancang sesuai dengan jumlah overburden yang akan digali setiap bulannya.

Tempat penimbunan dapat dibagi menjadi dua, yaitu waste dump/disposal dan stockpile. Waste dump/disposal adalah daerah pada suatu operasi tambang terbuka yang dijadikan tempat membuang material kadar rendah dan/atau material bukan bijih.

Ada tiga keadaan pengembangan material yaitu: bank condition, loose condition, dan compacted.

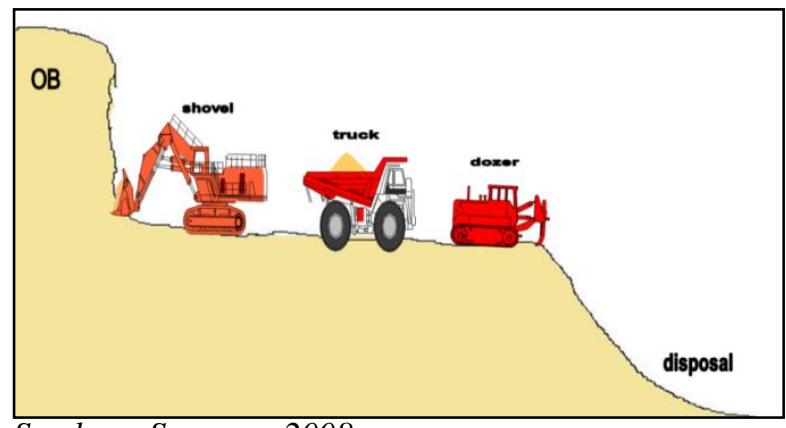

Sumber : Sunarno, 2008

\section{Gambar 2.1 Pemindahan Lapisan Overburden}

Disposal biasanya dibuat pada lubanglubang bekas penambangan ataupun bekas penambangan kuari. Ketika lubang tersebut 
telah penuh, maka permukaan dari disposal ini akan ditutupi dengan lapisan overburden (top soil) untuk dijadikan daerah penghijauan.

\subsection{Perencanaan Disposal}

Perencanaan material ke disposal menjadi hal yang sangat penting untuk direncanakan dalam membuat suatu rencana tahapan penambangan. Salah satu yang perlu diperhatikan dalam perencanaan material adalah keseimbangan material (material balance). Material balance berkaitan dengan pembagian material overburden ke tempat penimbunan (disposal) dengan memperhatikan faktor jarak angkut dan memaksimalkan ruang disposal.

Tempat penimbunan (disposal) dapat terbagi menjadi dua, yaitu :

a. Waste dump adalah suatu daerah pada operasi tambang terbuka dimana tanah penutup (overburden) dibuang.

b. Stockpile adalah suatu daerah yang digunakan untuk menyimpan batubara atau material yang akan digunakan diwaktu yang akan datang seperti top soil.

Waste dump ada dua macam, antara lain :

a. In pit dump (IPD) lokasinya pada daerah penambangan yang sudah selesai tambang.

b. Out pit dump (OPD) lokasinya berada di luar daerah pit limit (sterill area).

Perencanaan lokasi serta bentuk dari waste dump dan stockpile akan berpengaruh terhadap jumlah gilir truck (match factor) yang diperlukan, demikian pula biaya operasi yang diperlukan. Daerah yang diperlukan untuk waste dump pada umumnya luasnya 2-3 kali dari daerah penambangan (pit). Hal ini dipengaruhi oleh beberapa hal, antara lain : (Fino Arta, 2019)

a. Material yang dibongkar (loose material) berkembang 30-40\% dibandingkan dengan material in situ atau biasa disebut dengan swell factor.

b. Sudut kemiringan untuk suatu dump umumnya lebih lpenulisi dari pada pit.

c. Material pada umumnya tidak dapat ditumpuk setinggi kedalaman dari pit.

\subsection{Tipe-tipe Disposal}

Tipe-tipe disposal terdiri dari finger disposal, disposal tipe induced flow dan disposal tipe semi induced.

\section{Finger disposal}

Finger disposal adalah disposal yang dibuat maju dengan bantuan dozer. Disposal tipe ini memiliki ciri-ciri, yaitu ketinggian kurang dari 15 meter dengan kemiringan lereng yang lpenulisi kurang dari $40^{\circ}$. Dibutuhkan kontinuitas dari material sipil sebagai lpenulissan dump truck agar tidak terjadi longsoran.

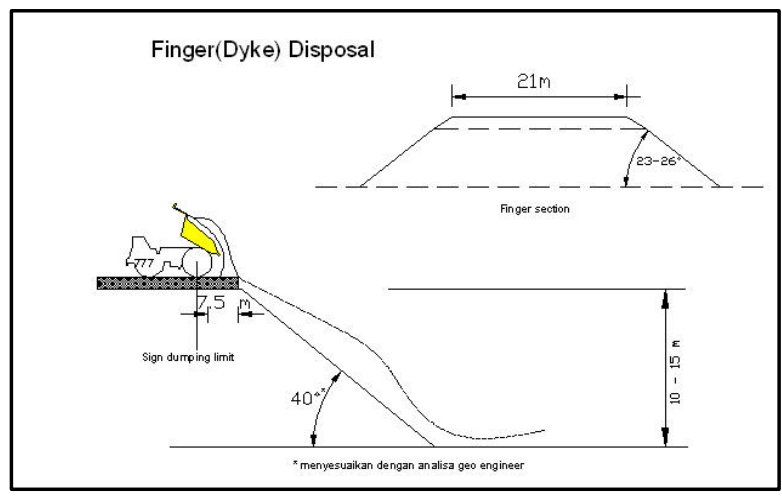

Sumber : Sunarno, 2008

\section{Gambar 2.2 Rancangan Finger Disposal}

Jika diperlukan dapat dibuat dyke untuk melindungi area yang belum terganggu dan untuk meningkatkan kapasitas disposal-nya. Sama seperti tipe dumping semi induced flow, material didorong dengan dozer hingga ujung lereng. Dozer mendorong material buangan dari jarak 7,5 meter dari crest yang merupakan posisi truck menongkang muatannya (Sunarno, 2008).

2. Disposal tipe induced flow

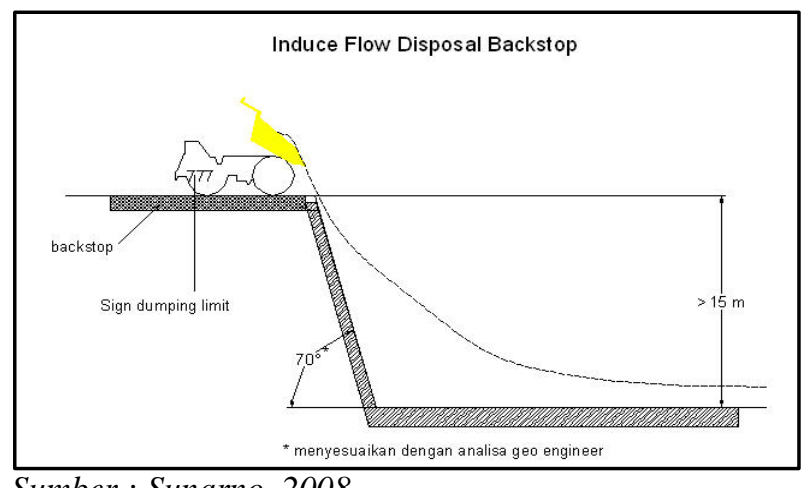

Sumber : Sunarno, 2008

Gambar 2.3 Rancangan Induced Flow 
Induced flow disposal adalah tipe disposal yang memanfaatkan beda ketinggian $>15$ meter untuk men-dumping material, dengan sudut kemiringan antara $50^{\circ}-70^{\circ}$. Disposal ini juga dilengkapi dengan backstop sebagai dudukannya (bund wall) setinggi setengah ban roda truk yang terletak pada ujung crest.

Disposal tipe induced flow disposal ini dibangun di atas tanah asli yang stabil (original), pada area blue zone atau pada area yang direkomendasikan oleh engineer geoteknik. Untuk mendorong material yang cukup padat ke bawah bisa disemprot dengan air. Selain itu, juga diperlukan instalasi alat pemantauan untuk mengamati ada tidaknya pergerakan tanah pada lereng, alatnya berupa inclinometer.

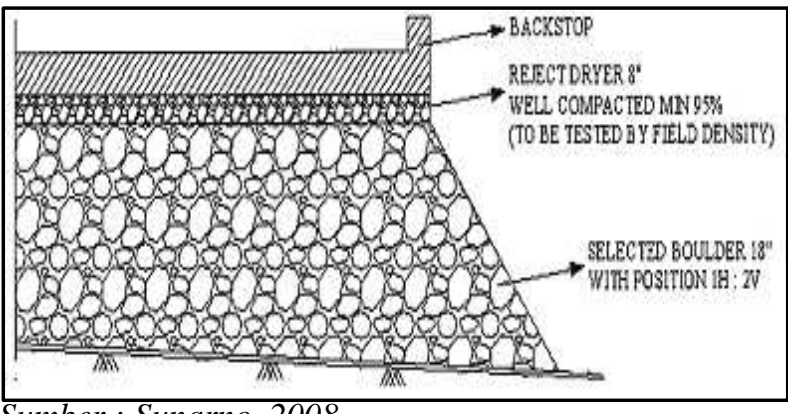

Sumber : Sunarno, 2008

\section{Gambar 2.4 Rancangan Backstop Induced Flow}

Kekurangan tipe induced flow disposal ini, yaitu tidak dapat diterapkan pada semua slope karena batuan lpenulissannya harus cukup kuat untuk menahan live road dari truk beserta muatannya hingga ke crest-nya, kapasitas disposal-nya kurang maksimal dan membutuhkan banyak biaya untuk pengadaan backstop (Sunarno, 2008).

\section{Disposal tipe semi induced flow}

Disposal semi induced flow pada umumnya sama atau memiliki kemiripan dengan induce flow tetapi truk hanya bisa dumping pada jarak tertentu yang diperbolehkan, yaitu $12,5 \mathrm{~m}$ dari original crest. Setelah itu, overburden didorong oleh dozer hingga ujung crest seperti pada gambar 2.5 .
Crest ke toe adalah 30 meter dengan kemiringan lereng antara $26^{\circ}-36^{\circ}$. Semi induce flow membutuhkan pembatuan material sipil pada lpenulissan truk yang akan menongkang untuk menambah daya dukung tanah agar tidak terjadi longsoran (subsidence).

Karena kemiringannya lebih besar, disposal tipe ini membutuhkan dozer yang lebih sedikit dari pada fnger flow. Namun, batas dorongan dozer pada disposal jenis ini tidak bergerak maju. Sebagai langkah antisipasi kelongsoran, perlu dilakukan pemantauan dengan alat extensometer (Sunarno, 2008).

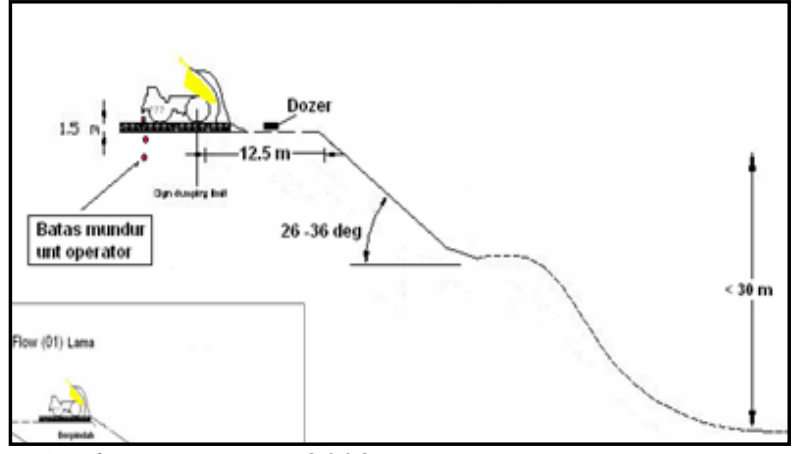

Sumber : Sunarno, 2008

Gambar 2.5 Semi Induced Flow Disposal dari Jenis-jenis Disposal

Kelebihan dari jenis ini, yaitu tidak mengeluarkan biaya untuk melakukan pembatuan di dumping area. Kekurangannya dibanding disposal induced flow adalah mengeluarkan biaya untuk pengadaan dozer dan apabila dibandingkan dengan finger disposal, kapasitas disposal-nya kurang maksimal.

\subsection{Software Minescape}

Minescape merupakan software perencanaan tambang terpadu yang dirancang khusus untuk industri pertambangan mencakup semua aspek informasi teknis tambang, mulai dari data eksplorasi hingga penjadwalan produksi tambang. Bagian mendasar dari Minescape adalah fitur sistem terbuka dan kemampuan untuk dikembangkan. Proses Minescape mendukung berbagai macam software aplikasi khusus yang memungkinkan penulis secara interaktif membuat dan 
mengolah model-model geologi tiga dimensi serta desain tambang. Sistem grafik CAD 3D yang hpenulisl dan dinamis merupakan inti dari sistem Minescape.

Minescape dirancang untuk digunakan oleh semua profesional tambang termasuk surveyor, geologist dan mine engineer. Fleksibilitas yang dimiliki oleh Minescape memastikan bahwa software tersebut dapat digunakan dalam perencanaan tambang jangka pendek dan jangka panjang untuk tambang batubara dan bijih. Minescape memiliki interface intuitif yang disebut graphical task interface (GTI). Interface tersebut menjadikan pekerjaan penulis lebih mudah dikerjakan sehingga lebih efisien dan mengurangi kebutuhan pelatihan.

Bagian-bagian penting yang terdapat pada menu program Minescape antara lain project, aplikasi-aplikasi Minescape, komponen-komponen interface.

Semua pekerjaan dalam Minescape didasarkan pada project-project yang secara umum disesuaikan dengan operasi tambang atau prospek eksplorasi. Project-project tersebut memungkinkan pekerjaan dapat dikelola secara logis sehingga memudahkan dalam manajemen dan pengaksesan. Minescape hanya mengijinkan bekerja pada satu project dalam satu session meskipun data dari project yang lain dapat diakses. Project tidak dapat diubah selama session Minescape. Apabila penulis ingin mengubah project, penulis harus keluar dari project dan pilih project baru. Beberapa session Minescape dapat dijalankan secara bersama-sama.

\subsection{Perhitungan Lebar Jalan Angkut}

Jalan angkut yang lebar diharapkan akan membuat lalulintas pengangkutan lancar dan aman. Namun, karena keterbatasan dan kesulitan yang muncul di lapangan, maka lebar jalan minimum harus diperhitungan dengan cermat.

\subsubsection{Lebar Jalan Angkut pada Jalan Lurus}

Lebar jalan minimum pada jalan lurus dengan lajur 2 lajur atau lebih, menurut AASHTO. Lebar jalan angkut pada jalan lurus dapat dirumuskan sebagai berikut:

$$
\operatorname{Lmin}=n \cdot W t+(n+1)(1 / 2 \cdot \mathrm{Wt})
$$

dimana :

$\mathrm{L}$ min = lebar jalan angkut minimum (m)

$\mathrm{n} \quad=$ jumlah lajur

$\mathrm{Wt}=$ lebar alat angkut $(\mathrm{m})$

\subsubsection{Lebar Jalan Angkut pada Jalan} Belokan

Untuk menghitung lebar jalan angkut pada jalan belokan dapat dihitung menggunakan persamaan berikut :

$$
\begin{gathered}
W=2(U+F a+F b+Z)+C \\
Z=\frac{(\mathrm{U}+\mathrm{Fa}+\mathrm{Fb})}{2}
\end{gathered}
$$

dimana :

$\mathrm{Wmin}=$ lebar jalan angkut minimum pada belokan (m)

$\mathrm{U} \quad=$ lebar jejak roda (center to center tires) $(\mathrm{m})$

$\mathrm{Fa}=$ lebar juntai (overhang) depan $(\mathrm{m})$

$\mathrm{Fb} \quad=$ lebar juntai belakang $(\mathrm{m})$

$\mathrm{Z} \quad=$ lebar bagian tepi jalan $(\mathrm{m})$

$\mathrm{C}=$ lebar antara kendaraan (total lateral clearance) (m)

\section{METODOLOGI PENELITIAN}

\subsection{Jenis Penelitian}

Jenis penelitian yang dilakukan dalam penelitian tugas akhir ini adalah penelitian yang tergolong kedalam jenis observasi dengan data berbentuk kuantitatif. Penelitian kuantitatif adalah suatu proses menemukan pengetahuan yang menggunakan data berupa angka sebagai alat menganalisis keterangan mengenai apa yang ingin diketahui (Kasiram (2008 : 149).

\subsection{Waktu dan Tempat Penelitian}

Kegiatan yang dilakukan untuk pengambilan data ini di PT Bukit Asam, Tbk.. Waktu penelitian dilaksanakan pada tanggal April s.d. Mei 2019.

\subsection{Metode Penelitian}

Dalam metode penelitian ini terdapat cara pengambilan data, jenis data, pengolahan data, analisis hasil pengolahan data, serta kesimpulan dan saran.

\section{Cara Pengambilan Data}

Metode pengambilan data yang digunakan dalam penelitian ini adalah:

a. Studi literatur 
Studi literatur dilakukan dengan mencari informasi dan teori yang berhubungan dengan Rencana Desain Backfilling dan Perhitungan Volume Material Timbunan Menggunakan Software Minescape 4.118 untuk Memenuhi Target Produksi Di PT Bukit Asam, Tbk. Tanjung Enim, Sumatera Selatan yang menjadi acuan dalam penulisan penelitian ini.

b. Observasi lapangan

Observasi lapangan dilakukan dengan mengamati desain disposal yang ada di PT Bukit Asam, Tbk..

2. Jenis data

Jenis data yang digunakan di penelitian ini adalah :

a. Data primer

Data primer antara lain:

1) Lebar jalan angkut overburden,

2) Data jarak angkut dari front penambangan ke disposal, dan

3) Data alat gali muat dan alat angkut yang digunakan.

b. Data sekunder

Data sekunder antara lain:

1) Data stratigrafi,

2) Data litologi,

3) Data peta situasi areal penambangan,

4) Data geoteknik,

5) Data target dan produksi overburden,

6) Data curah hujan bulan April tahun 2019

7) Sequence timbunan bulan April tahun 2019

8) Parameter fisik dan mekanik timbunan

3. Pengolahan Data

Data-data yang telah diperoleh kemudian diklasifikasikan berdasarkan jenis data kemudian dilakukan analisis serta perhitungan sesuai dengan kebutuhan dan tujuan dari penelitian tugas akhir ini.

Pada pengolahan data, software paint berfungsi untuk mengubah format gambar hasil plotting dari software Minescape dari format emf ke format jpg.

4. Analisis Hasil Pengolahan Data

Data-data yang ditemukan diolah agar dapat membuat rancangan disposal area. Pada tahap ini pengolahan data menggunakan perangkat lunak Minescape 4.118. Melakukan analisis data hasil pengolahan untuk memberikan alternatif penyelesaian masalah sebagai acuan membahas permasalahan yang telah dikemukakan dengan membuat sebuah penyusunan secara sistematis, faktual, dan cermat. Tahap ini mengacu kepada studi pustaka sebagai pelengkap dan sebagai korelasi data yang sudah didapatkan di lapangan sehingga tercipta suatu solusi yang tepat terhadap permasalahan yang ditemui dilapangan.

5. Kesimpulan dan Saran

Hasil data keseluruhan dirangkum ke dalam laporan tertulis untuk dipertanggungjawabkan dalam bentuk laporan hasil penelitian.

\section{HASIL DAN PEMBAHASAN \\ 4.1 Pembuatan Desain Disposal}

Pembuatan desain disposal adalah parameter rancangan yang telah ditentukan oleh geoteknik tambang. Pembuatan desain disposal yang direncanakan oleh pihak perusahaan hanya sebesar $1.500 .000 \mathrm{CCM}$ pada bulan April tahun 2019 dengan target produksi 1.700.000 CCM. Oleh karena itu, asumsi parameter-parameter yang dipersiapkan dalam merancang desain disposal di area pit barat Muara Tigas Besar agar dapat tercapai target produksi adalah ketinggian bench 6 meter, lebar bench 25 meter, kemiringan bench $18^{\circ}$. Sedangkan lebar jalan angkut untuk overburden adalah 25 meter, grade jalan $8 \%$.

\subsubsection{Peta Situasi}

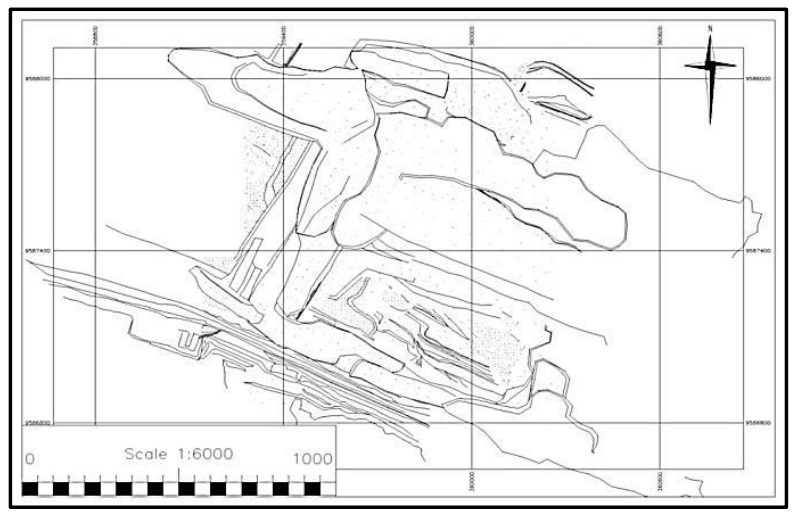

Gambar 4.1 Peta Situasi

Peta situasi merupakan peta yang bisa menggambarkan kondisi lapangan baik posisi 
horizontal, maupun posisi ketinggiannya. Peta situasi disposal pit barat Muara Tiga Besar di PT Bukit Asam, Tbk..

Tabel 4.1 Data Geoteknik Disposal Pit Barat MTB

\begin{tabular}{|l|l|}
\hline $\begin{array}{l}\text { Parameter-parameter } \\
\text { Geoteknik }\end{array}$ & Keterangan \\
\hline Bench Height & 6 meter \\
\hline Bench Widht & 22 meter \\
\hline Bench Slope & $18^{\circ}$ \\
\hline
\end{tabular}

Sumber : Satuan Kerja Renop, 2019

\subsubsection{Pembuatan Boundary}

Boundary merupakan batasan luas area suatu wilayah penimbunan ataupun penambangan. Pembuatan boundary desain berguna untuk menentukan batasan luas area penimbunan yang akan dibuat.

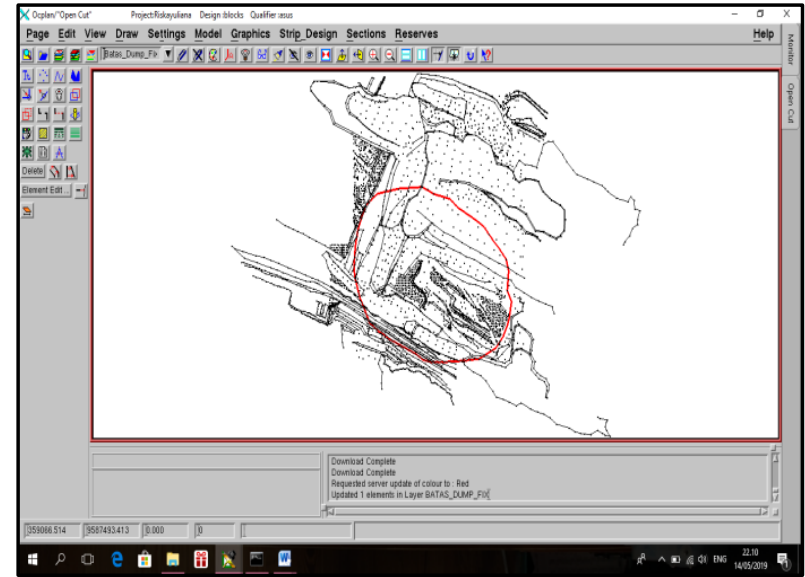

Gambar 4.3 Boundary

\subsubsection{Pembuatan Project and Offset}

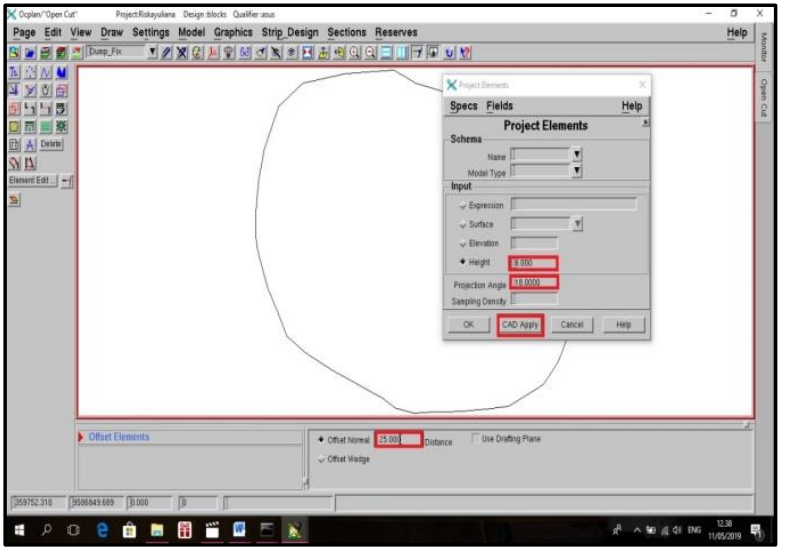

Gambar 4.4 Project and Offset

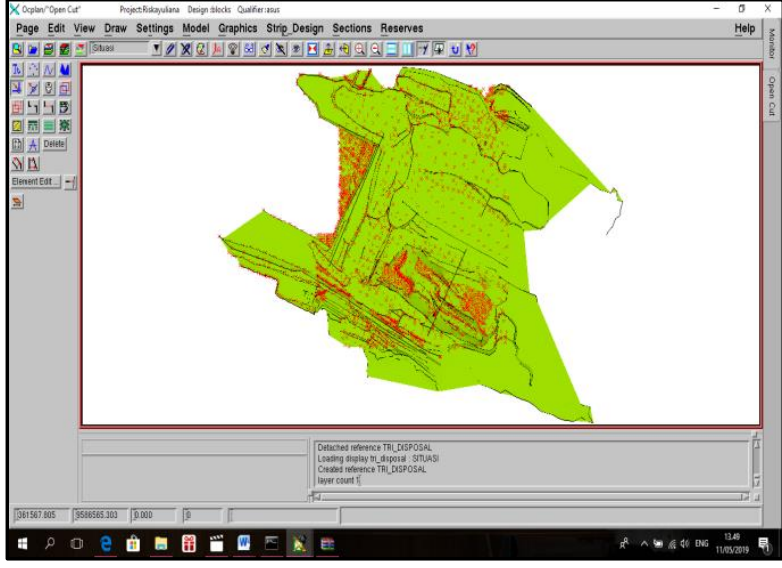

Gambar 4.5 Hasil Apply Project and Offset

\subsubsection{Pembuatan Triangles}

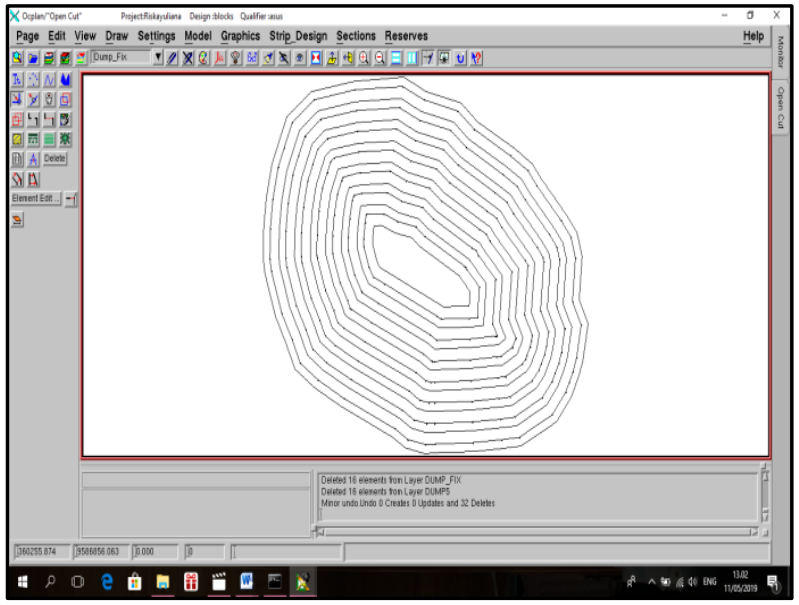

Gambar 4.7 Hasil Triangles Desain Situasi

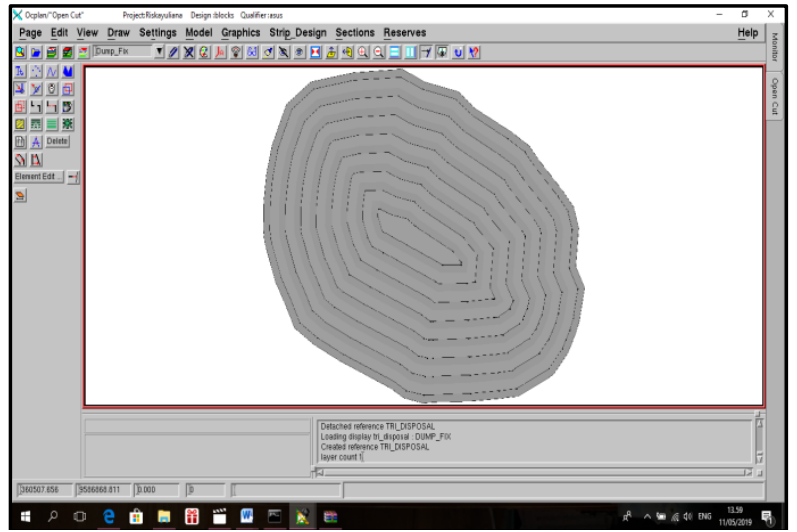

Gambar 4.8 Hasil Triangles Desain Disposal

\subsubsection{Pembuatan Intersection Desain Disposal dan Situasi \\ Intersection merupakan perintah yang} berfungsi untuk memotong antara desain disposal dengan situasi, sehingga akan 
terbentuk garis baru dari hasil intersection tersebut.

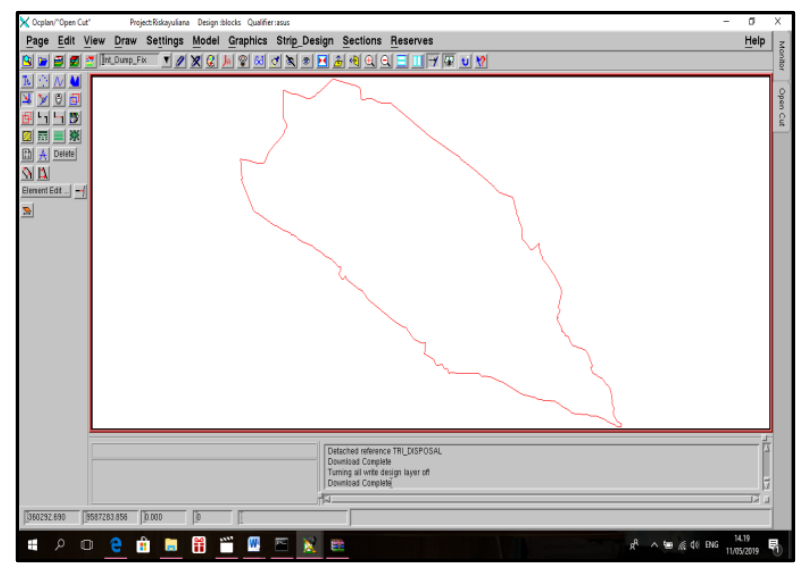

Gambar 4.10 Polygon Hasil Intersection

\subsubsection{Clip World}

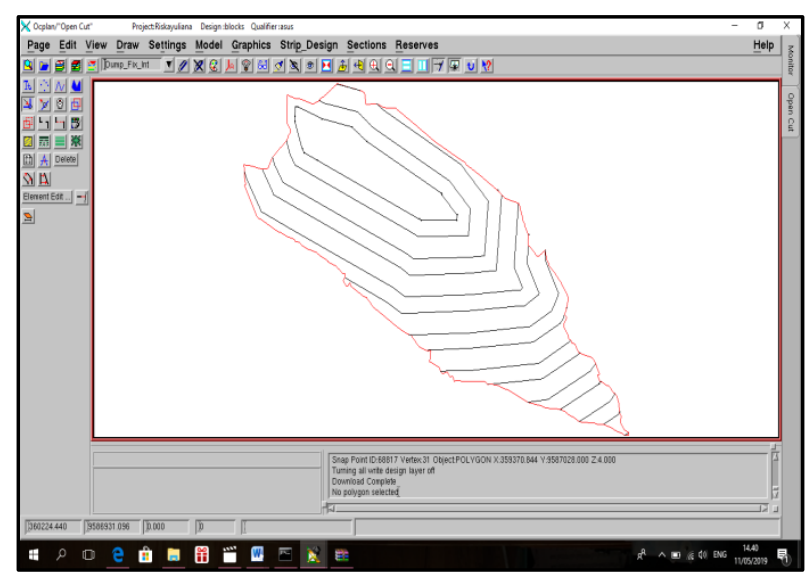

Gambar 4.12 Hasil Clip World

Triangles desain disposal yang telah di clip world tadi digabungkan dengan triangles situasi maka akan terlihat seperti pada gambar 4.13.

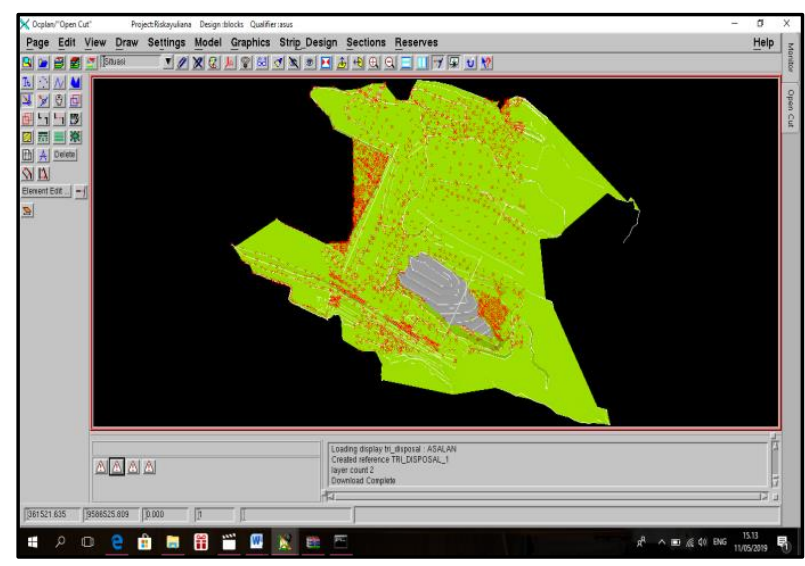

Gambar 4.13 Hasil Triangle Desain Disposal dan Situasi

\subsubsection{Cross Section}

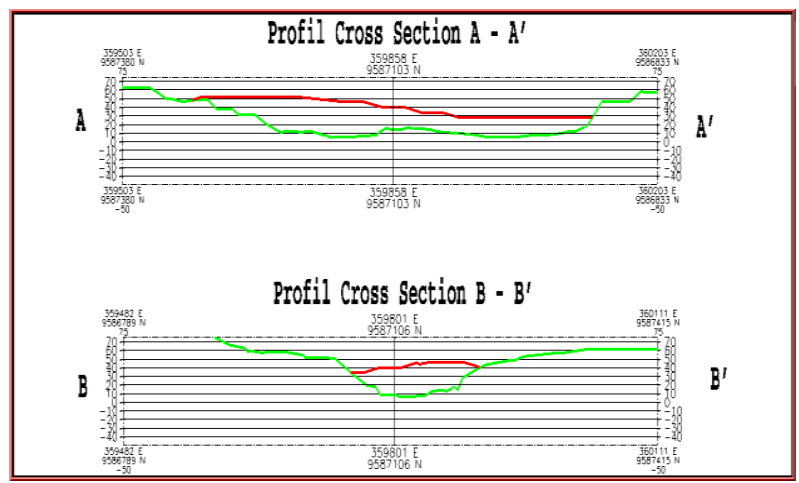

Gambar 4.15 Hasil Cross Section

\subsubsection{Plotting}

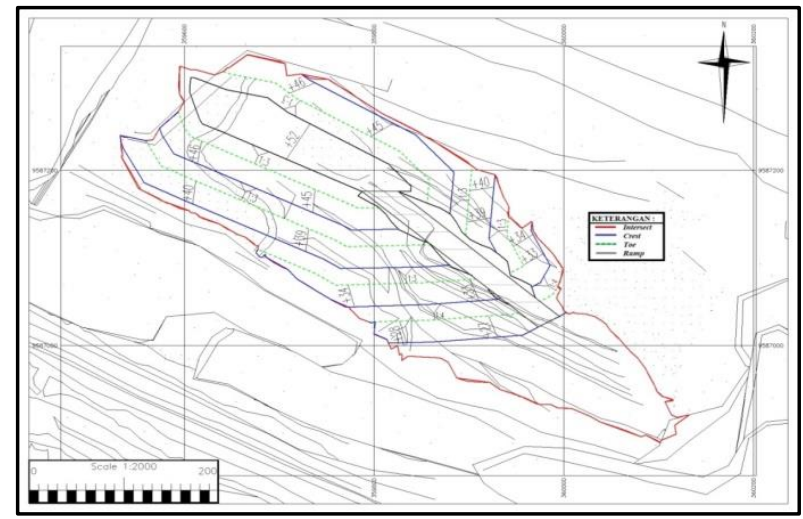

Gambar 4.16 Hasil Plotting

Dengan membuat lebar bench $25 \mathrm{~m}$ dengan hasil produksi 1.724.805,98 CCM bahwa target produksi dapat tercapai optimal, karena telah di buat lebar bench $24 \mathrm{~m}$ produksi tidak tercapai secara optimal sebesar 1.655.813,74 CCM. Lebar jalan angkut dibuat sebesar $25 \mathrm{~m}$ karena sebelumnya hanya $23 \mathrm{~m}$, lebar jalan angkut dibuat sebesar $25 \mathrm{~m}$ karena menggunakan rumus perhitungan sesuai dengan AASHTO.

\subsection{Perhitungan Volume Timbunan}

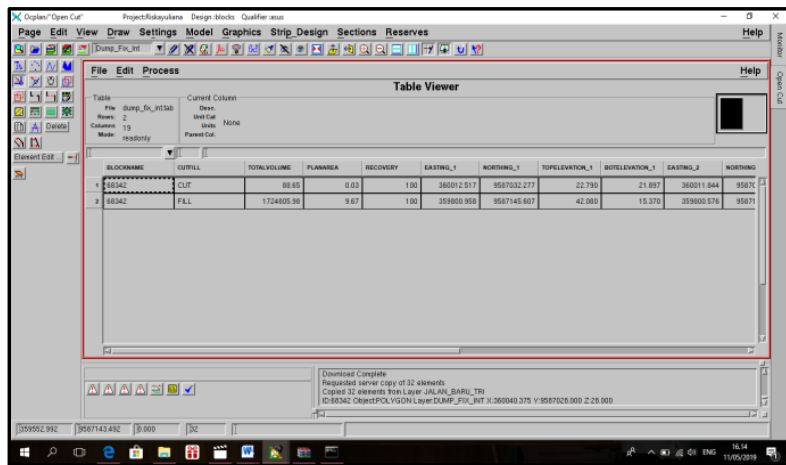

Gambar 4.18 Hasil Perhitungan Volume 


\subsection{Volume Overburden}

Volume overburden di pit Barat dengan material clay siltstone dengan menggunakan asumsi parameter yang telah dibuat menggunakan alat angkut Komatsu HD 785-7 11 unit dengan alat gali muat Komatsu PC 2000-8 sebanyak 1 unit, Komatsu PC 1250-8 sebanyak 1 unit, Komatsu PC 800-8 sebanyak 1 unit, untuk bulan April tahun 2019 dengan jarak sejauh 2400 meter dari front penambangan ke disposal. Pada bulan April tahun 2019 target produksi yang ditetapkan oleh perusahaan sebesar 1.700.000 CCM.

Tabel 4.2 Perbandingan Produksi

\begin{tabular}{|l|l|l|}
\hline $\begin{array}{l}\text { Menggunakan } \\
\text { Software } \\
\text { Minescape } \\
\text { (CCM) }\end{array}$ & $\begin{array}{l}\text { Realisasi di } \\
\text { Lapangan } \\
\text { (CCM) }\end{array}$ & $\begin{array}{l}\text { Target } \\
\text { Produksi } \\
\text { (CCM) }\end{array}$ \\
\hline $1.724 .805,98$ & 1.500 .000 & 1.700 .000 \\
\hline
\end{tabular}

Tabel 4.3 Penggunaan Alat Gali Muat dan Alat Angkut untuk Overburden

\begin{tabular}{|l|l|c|c|c|}
\hline \multicolumn{2}{|l|}{ Alat Berat } & $\begin{array}{l}\text { Jumlah } \\
\text { Unit } \\
\text { (unit) }\end{array}$ & $\begin{array}{l}\text { Kapasitas } \\
\text { Bucket } \\
\left(\mathrm{m}^{3}\right)\end{array}$ & $\begin{array}{l}\text { Kapasitas } \\
\text { Vessel } \\
\left(\mathrm{m}^{3}\right)\end{array}$ \\
\hline \multirow{4}{*}{$\begin{array}{l}\text { Alat } \\
\text { Gali } \\
\text { Muat }\end{array}$} & $\begin{array}{l}\text { Komatsu } \\
\text { PC } \\
2000-8\end{array}$ & 1 & 12 & - \\
\cline { 2 - 5 } & $\begin{array}{l}\text { Komatsu } \\
\text { PC } \\
1250-8\end{array}$ & 1 & 6,7 & - \\
\cline { 2 - 5 } & $\begin{array}{l}\text { Komatsu } \\
\text { PC 800- } \\
8\end{array}$ & 1 & 3 & - \\
\hline Alat & $\begin{array}{l}\text { Komatsu } \\
\text { Angkut 785- } \\
7\end{array}$ & 11 & - & 60 \\
\hline
\end{tabular}

Sumber : Satuan Kerja Renop (paket 10-200),2019

\section{KESIMPULAN DAN SARAN}

\subsection{Kesimpulan}

Dari hasil pembahasan yang telah dilakukan, maka didapatkan kesimpulan sebagai berikut :

1. Untuk rencana desain backfilling parameter-parameter yang sangat diperlukan untuk pembuatan desain backfilling ialah peta situasi atau peta yang bisa menggambarkan kondisi lapangan baik posisi horizontal, maupun posisi ketingiannya, dan data geoteknik.

2. Perhitungan volume timbunan desain backfilling yang didapatkan menggunakan software Minescape 4.118 dengan menggunakan menu bar 'reserves' cut and fill adalah sebesar 1.724.805,98 CCM untuk mencapai target produksi sebesar 1.700 .000 CCM

3. Perbandingan volume timbunan menggunakan software Minescape dengan realisasi di lapangan adalah untuk di lapangan sebesar $1.500 .000 \quad \mathrm{CCM}$ sedangkan menggunakan software Minescape sebesar 1.724.805,98 CCM dengan desain yang dibuat sesuai dengan asumsi parameter.

\subsection{Saran}

Saran yang dapat diberikan dari penelitian ini, yaitu :

1. Perlebaran jalan angkut dengan minimal lebar jalan angkut $24 \mathrm{~m}$ sesuai dengan alat angkut HD 785-7.

2. Pengambilan data xyz (point) untuk desain disposal di lapangan lebih diperkecil jarak pengambilan point-nya, dikarenakan jika terlalu renggang, maka pada saat diakukan perhitungan volume menggunakan software Minescape 4.118 akan mempengaruhi jumlah total volume timbunan yang akan dihitung.

\section{DAFTAR PUSTAKA}

Irwandi, Arif dan Gatut Adisoma. 2002. Perencanaan Tambang. Bandung: Institut Teknologi Bandung.

Sudrajat, N. 2013. Pertambangan Indonesia.

Yogyakarta: Pustaka Yustisia.

Sunarno, P. 2008. Standard Job Procedure Perencanaan dan Pelaksanaan Disposal. Mining Departement PT Inco, Tbk..: Sorowako. 
P-ISSN: 2089-5925 E-ISSN: 2621-9328

Antrant

Jurnal Teknik Patra Akademika

PA

A KaAemiKa

Volume 09 No 01 Juli 2018 